\title{
EL «ENRIQUECIMIENTO SIN CAUSA» EN DERECHO INTERNACIONAL Y SU INCIDENCIA EN LA DETERMINACIÓN DE LA LEY APLICABLE A LAS RELACIONES PRIVADAS INTERNACIONALES
}

\author{
LYDIA ESTEVE GONZÁLEZ \\ Profesora de Derecho internacional privado \\ Universidad de Alicante
}

\begin{abstract}
«Las situaciones puras, nítidas, serán poco frecuentes y progresivamente iremos asistiendo a una ordenación jurídica en que lo público y lo privado, lo estatal y lo internacional se mezclan, pero con la particularidad de previamente experimentar entre estos sectores influencias recíprocas y modificantes» (M. Aguilar Navarro) ${ }^{1}$.
\end{abstract}

\section{PLANTEAMIENTO}

1. La institución jurídica del «enriquecimiento sin causa», propia del Derecho civil patrimonial, intenta evitar o corregir en su caso las transferencias patrimoniales injustas. Todo en ella es motivo de discusión y controversia comenzando por sus orígenes, prosiguiendo con su denominación y finalizando con su aplicabilidad práctica, lo que indica la falta de delimitación de la noción y del concepto «enriquecimiento sin causa». Y es que el enriquecimiento injusto es un principio general del Derecho reconocido implícita o explícitamente en todos los ordenamientos jurídicos y sus funciones deben constreñirse, por tanto, a la de todo principio general, destacándose entre ellas la de informar tanto el ordenamiento jurídico cuanto la aplicación de los poderes normativos ${ }^{2}$. Conviene, en consecuencia, distinguir el enriquecimiento injusto, principio general del Derecho, del enriquecimiento sin causa ${ }^{3}$, fuente autónoma de las obligaciones infor-

1 Cfr., M. Aguilar Navarro, Ensayo de delimitación del Derecho internacional económico, Universidad Complutense de Madrid, Madrid, 1972, p. 25.

2 Sobre las funciones de los principios generales del Derecho, vid., inter alia, M. Atienza y J. Ruiz Manero, «Sobre principios y reglas», DOXA, 10, 1991, pp. 101 y ss.

3 Esta distinción ha sido apuntada en la doctrina española por M. de la Cámara en L. DíezPicazo y M. de la Cámara Álvarez, Dos estudios sobre el enriquecimiento sin causa, Madrid, Civitas, 1988, pp. 137 y ss. 
mada por aquél y distinta del contrato y del delito que algunos sistemas jurídicos regulan expresamente no sólo en Derecho material sino también en sus respectivos sistemas de Derecho Internacional Privado (en adelante Dipr.) ${ }^{4}$ y respecto de la cual existen a su vez distintas concepciones - la que entiende que es un cuasicontrato, que es una fuente autónoma de las obligaciones que sustituye a la arcaica noción de cuasicontrato y acoge al cobro de lo indebido en su ámbito de aplicación, una obligación legal o es sencillamente un principio general ${ }^{5}$ - que repercuten en la exigencia de determinados requisitos y en su aplicabilidad práctica.

2. El presente trabajo parte de un dato fácilmente constatable: la incidencia del enriquecimiento injusto y sin causa en el Derecho público, en el Derecho internacional general y en el Derecho comunitario ${ }^{6}$ y su análisis se incardina en una perspectiva iusinternacional privatista que tan sólo recoge - sin ánimo de exahustividad - determinados datos aportados por el Derecho internacional público (en adelante Dip) que permitirán abordar la aplicación de la «dogmática del enriquecimiento sin causa» en las situaciones privadas internacionales como «principio general del Derecho reconocido por todas las naciones civilizadas» y susceptible de ilustrar el orden público internacional.

Teniendo presente este razonamiento parece oportuno estudiar, en primer término, el grado de incidencia del enriquecimiento injusto y sin causa en otros sectores del Derecho (II); en segundo lugar, la proyección de la fuente autónoma de las obligaciones enriquecimiento sin causa en Dip., tratando de dilucidar si su aplicación a las relaciones internacionales se efectúa como institución de Derecho interno o de Derecho internacional (III); en tercer término, la proyección en Dip del principio general del Derecho enriquecimiento injusto, su aplicación como principio de Derecho interno o como principio de Derecho internacional y su función ilustrativa del orden público internacional (IV); y, por último, la incidencia del Derecho internacional general en el sector del Derecho aplicable a una relación privada heterogénea en la que se ha producido un enriquecimiento injusto $(\mathrm{V})$.

$4 \quad V i d$., entre otros, los sistemas suizo, austríaco y portugués.

5 J.A. Álvarez Caperochipi (El enriquecimiento sin causa, Granada, Comares, 1993, pp. 17 y ss.) afirma que existen cuatro concepciones de enriquecimiento sin causa: como principio general del derecho, como fundamento o complemento de la técnica cuasicontractual, como acción subsidiaria o como acción principal.

6 Sobre la proyección del enriquecimiento sin causa en Derecho comunitario, vid., por todos, L. Esteve González, «Fundamento y ejercicio de la Condictio indebiti en Derecho comunitario», $L a$ Ley. Comunidades Europeas, 28 diciembre 1993, pp. 1-7. 


\section{EL ENRIQUECIMIENTO INJUSTO Y SIN CAUSA EN EL DERECHO PÚBLICO Y EN EL DERECHO INTERNACIONAL}

3. En los Derechos positivos vigentes de corte europeo-occidental las relaciones entre individuos son objeto del Derecho privado y las relaciones entre individuos y el poder soberano lo son del Derecho público, reservándose al Dipr. la labor de dar respuesta a las relaciones privadas de tráfico jurídico internacional. Pero si hoy no es difícil reconocer la evidente repercusión de la incidencia de los poderes públicos en las relaciones privadas, por lo tanto del Derecho público sobre el Derecho privado, tampoco lo es el reconocimiento de la incidencia del Derecho privado sobre el Derecho público.

La doctrina del enriquecimiento también ha visto la luz en el ámbito del Derecho público, constituyéndose en un claro ejemplo de la incidencia del Derecho privado sobre este último al penetrar operativamente en sectores tan dispares como el Derecho administrativo o el Derecho financiero y tributario 7 . El principio de enriquecimiento injusto no parece difícilmente trasladable al campo del Derecho público - muy especialmente en aquellos sectores que afectan al cobro, gestión o gasto del ahorro resultante de los tributos u otras actividades del Estado y ello debido a su carácter patrimonial y al contenido general que obliga a la restitución de lo adquirido indebidamente, al prohibir que se produzcan desplazamientos patrimoniales injustos. De este contenido general puede derivarse la prohibición de dichos desplazamientos injustos acaecidos tanto entre sujetos privados cuanto públicos. Aquellos supuestos en que el principio general del Derecho sea invocado en sectores propios del Derecho financiero, tributario, Derecho de la seguridad social o administrativo quedarán, claro está, fuera del objeto del

7 Esto sin duda es más fácil de comprender en los sistemas del ámbito del Common Law donde no existe una clara distinción entre Derecho público y Derecho privado. Verbi gratia, uno de los casos más conocidos de enriquecimiento sin causa de la jurisprudencia estadounidense, Maricopa Countr c. Avondale (1970), hace referencia precisamente a un litigio entre un Ayuntamiento y un condado de Arizona por la aplicación errónea de ingresos fiscales (vid. J. P. Dawson, «Restitution without enrichment», Boston University Review, 61, 1981, pp. 563 y ss.; y G. Jones, Restitution in Public and Private Law, Londres-Bombay, Sweet y Mazwell-Tripathi, 1991). El TS español, por su parte, ha aplicado el principio general de enriquecimiento injusto más allá del campo del Derecho privado para invocarlo como fuente de responsabilidad de la Administración pública (vid. E. García Enterría, Curso de Derecho Administrativo, vol. II, $3^{\text {a }}$ ed., Civitas, Madrid, 1991, pp. 386 y ss.; y F. Garrido Falla, Tratado de Derecho administrativo, vol. II, Madrid, Tecnos, 1992, pp. 28 y ss.); también ha sido aplicado como protector del contribuyente frente a ingresos fiscales indebidos (vid. STS. (Sala $3^{\text {a }}$ ) de 27 nov. 1981 y su comentario por A. Martínez Lafuente, «El enriquecimiento sin causa en Derecho Financiero», Civitas REDF, núm. 36, 1982, pp. 657 y ss.; R. Mateu-Ros Cerezo, Devolución de ingresos tributarios indebidos y revisión por infracción de la ley, Madrid, Civitas, 1985, p. 46; y además, A. Novoa Rivas, «Incidencias del enriquecimiento injusto en el Derecho tributario», R.D.P., t. LVII, 1973, pp. 925 y ss.). Advirtiendo, no obstante, del peligro de la utilización de la acción en el sector de la administración pública, vid., por todos, J.A. Álvarez-Caperochipi, cit., pp. 183 y ss. 
Dipr., y ello no porque no puedan producirse «conflictos de leyes» en estos sectores jurídicos sino porque el objeto del Derecho internacional privado se explica por el hecho de que los sujetos de dicha relación son sujetos de Derecho privado o de Derecho público que actúan con carácter privado, es decir, se circunscribe al estudio de las situaciones privadas internacionales ${ }^{8}$. Ahora bien, partiendo de tal consideración de relación jurídica, «el problema - y no es baladí- consiste en determinar in casu cuándo nos encontramos ante una situación de este tipo y cuándo, por el contrario, la relación se establece entre dos Estados o entre un ente público y un particular, actuando aquél investido de soberanía» ${ }^{9}$. Por lo que hace referencia a la concepción y ejercicio de la acción de enriquecimiento sin causa en el ámbito del Derecho público no hay que olvidar que dicha acción es personal - y con unos requisitos preestablecidos- y que en este contexto sería ejercitable por una persona privada —o pública pero que actúa con carácter privado- frente a un sujeto de Derecho público o viceversa ${ }^{10}$.

En definitiva, la teoría del enriquecimiento ha traspasado las fronteras del Derecho privado y los distintos Derechos materiales internos para proyectarse también en el Derecho público y, muy especialmente, en el Derecho comunitario y en el Dip., proyección que arrastrará todas las deficiencias delimitativas que posee el instituto en Derecho interno. Por ello, habrá de tenerse en cuenta que la expresión «enriquecimiento sin causa» puede hacer referencia en Dip. al principio general del Derecho que se ha venido denominando enriquecimiento injusto o, por el contrario, a la institución autónoma o acción de enriquecimiento sin causa y, por otra parte, deberá observarse la incidencia de las distintas concepciones de la doctrina del enriquecimiento - anteriormente expuestas- sobre el Dip.

\section{LA DOGMÁTICA DEL ENRIQUECIMIENTO SIN CAUSA EN LA DOCTRINA Y JURISPRUDENCIA INTERNACIONAL}

\section{Proyección de la concepción de cuasicontrato y de la fuente autónoma de las obligaciones de enriquecimiento sin causa}

4. En uno de los primeros trabajos de la doctrina internacionalista española sobre el «enriquecimiento sin causa» A. Miaja de la Muela ${ }^{11}$ señalaba que la

8 Vid. por todos, J. C. Fernández Rozas y S. Sánchez Lorenzo, Curso de Derecho internacional privado, $2^{\mathrm{a}}$ ed., Madrid, Civitas, 1993, p. 53.

9 M. Desantes Real, Proyecto docente e investigador, Alicante, 1992, p. 96.

10 Cuestión diferente sería plantear si el traslado de instituciones jurídicas pertenecientes al Derecho privado puede realizarse sin reservas ya que, obviamente, los intereses subyacentes en el ámbito del Derecho público no parecen ser los mismos que en el ámbito del Derecho privado. En este sentido, A. Martínez Lafuente («El enriquecimiento sin causa...», cit. p. 659) propone hablar de 'supraconceptos' (la cursiva es mía) pertenecientes a la teoría general del Derecho que deben tener una concreta especificación en cada una de las disciplinas jurídicas en particular». 
trasposición de las técnicas y reglas del Derecho privado interno a las relaciones internacionales por obra de los expositores del Derecho de gentes, tanto los pertenecientes a la Escuela española del siglo XVI cuanto Groccio y sus sucesores, es un hecho indiscutible. En efecto, la doctrina y — de la mano de ésta- la práctica internacional han promovido la utilización de instituciones propias del Derecho privado o del Derecho civil ${ }^{12}$, quedando patente -al tratarse de una importación del Derecho interno- el reflejo de los distintos enfoques de la doctrina privatista y, posteriormente, de los textos positivos de Derecho privado: se recuerda que, mientras gran parte de las codificaciones del siglo XIX — verbi gratia, la francesa, belga o española - recogieron la categoría del cuasicontrato, el BGB alemán y otros códigos civiles del siglo XX por influencia de este último -así, el Código civil suizo y turco de las obligaciones o los Códigos civiles austríaco, italiano, griego o portugués- descartan la arcaica figura del cuasicontrato para regular en su lugar la gestión de negocios ajenos y el enriquecimiento sin causa como fuente de las obligaciones.

5. Lo anterior ha repercutido en la doctrina iusinternacionalista en una doble vertiente: por un lado, sobre la admisión o no de la noción de cuasicontrato -reflejo constatable de la anunciada «crisis del cuasicontrato» ${ }^{13}$ — en Dip.; por otro, sobre la conveniencia de trasponer al Dip. las categorías de gestión de negocios ajenos y de enriquecimiento sin causa -e, incluso, cobro de lo indebido- como instituciones autónomas ${ }^{14}$. La cuestión es controvertida. En efecto, la proyección de la concepción del cuasicontrato y del enriquecimiento sin causa como institución autónoma, como indica E. Fanada ${ }^{15}$, fue impugnada por diversos autores como Cavaglieri, Vattel, Kunz o Balladore-Parielli, mientras que otros como Heffer, Seligman, Donati, Romano o Wengler han defendido la presencia de los cuasicontratos en Derecho internacional. Junto a ellos, Udina, Padrier-Fodéré, Rivier, Despagnet o Nys estiman posible trasponer las categorías de negotiorum

11 Vid. A. Miaja de la Muela, «El principio del enriquecimiento sin causa en Derecho internacional», Symbolae García Arias, Temis, Zaragoza, 1973-74, pp. 349 y ss.

12 Sobre la aplicación de las reglas de Derecho civil a las relaciones internacionales, vid. G. Ripert, «Les règles de droit civil applicables aux rapports internationaux», Rec. des cours, 1933-II, t. 44 , pp. 569 y ss.

13 La inutilidad de la noción de cuasicontrato ha sido destacada por numerosos autores. Vid. inter alia, J. Carbonnier, Thèorie des Obligations, París, Temis, 1963, p. 451; H. Vizioz, La notion du cuasi-contrat, Tesis, Bordeaux, 1912; y M. Albadalejo, Curso de Derecho civil español, vol. II, $3^{\text {a }}$ ed. Barcelona, Bosch, 1984, p. 548.

14 Un estudio exhaustivo de la dogmática general de estas instituciones desde la concepción romanística de obligaciones quasi ex contractu hasta su recepción al Derecho internacional general - analizada fundamentalmente a la luz de la doctrina italiana y alemana- es realizado por E. Fanara, Gestione di affari e arrichimento senza causa nel Diritto Internacionale, Milán, Dott. A. Giuffe, 1966.

15 E. Fanara, op. cit., pp. 1-33. 
gestio, communio incidens - como se sabe, antiguo cuasicontrato romano-y enriquecimiento sin causa a las relaciones internacionales ${ }^{16}$.

6. La práctica internacional nos ilustra con un ejemplo relativo a la aplicación de la noción de cuasicontrato acaecido a principios de siglo: el asunto de las reclamaciones británicas contra España por hechos que tuvieron lugar en lo que fue Zona española de protectorado en Marruecos. El laudo arbitral de 1 de mayo de 1927 que resolvió este litigio admitió la obligación de resarcir como una manifestación de las obligaciones quasi ex contractu afirmando que «...el árbitro hace constar ante todo la existencia de un principio jurídico generalmente admitido: aquel según el cual las obligaciones cuasicontractuales pueden nacer de los actos unilaterales. Hace constar también que la ocupación de un inmueble por las autoridades, sin la aquiescencia del propietario, sin un procedimiento de expropiación y sin la excusa de necesidad militar (...) reúne las características necesarias para que sea posible deducir a cargo de las autoridades, y en favor del propietario, obligaciones quasi ex contractu». E. Fanara ${ }^{17}$ entiende que si se acudió a la figura genérica de cuasicontrato en lugar de hacerlo a la específica de enriquecimiento sin causa fue porque para la aplicación de esta figura faltaba el requisito esencial del empobrecimiento del demandante. A. Miaja de la Muela ${ }^{18}$ advierte, sin embargo, que probablemente se recurrió al concepto de cuasicontrato por estar dicha noción recogida en el Código civil español y no así la figura del enriquecimiento sin causa.

De lo anterior se desprende que la aplicación del enriquecimiento sin causa como cuasicontrato no se produce en tanto que aplicación del Derecho internacional sino del Derecho interno en el sentido de autónomo o estatal, afirmación que permite estudiar el siguiente apartado.

\section{Aplicación del enriquecimiento sin causa como institución de Derecho interno de los Estados (cuestión de derecho aplicable) y como institución de Derecho internacional}

7. La jurisprudencia arbitral internacional sobre «enriquecimiento sin causa» es bastante abundante y ha sido recogida con rigurosidad por E. Fanara ${ }^{19}$. No

16 E. Fanara, op. cit., pp. 1-33.

17 E. Fanara, op. cit. p. 224.

18 A. Miaja de la Muela, «El principio de enriquecimiento...», cit., p. 358.

19 Vid. E. Fanara, op. cit. supra. Vid. también CH. Schreuer, «Unjust Enrichment in international Law», $A J C L, 1974$, pp. 281 y ss. El enriquecimiento injusto analizado desde la perspectiva de la teoría general de la responsabilidad internacional ha sido abordado por B. Cheng, General principles of Law as applied by international Courts and Tribunals, Londres, 1953, pp. 236 y ss. Siguiendo esta última dirección hay que destacar la valiosa aportación que supone, dentro de la doctrina iusinternacionalista española, el trabajo de G. C. Rodríguez Iglesias, «El enriquecimiento sin causa como fundamento de la responsabilidad internacional», Revista Española de Derecho internacional (REDI), 1982, pp. 382 y ss. 
obstante, y como indica G. C. Rodríguez Iglesias ${ }^{20}$, el valor de esta jurisprudencia internacional debe ser cuidadosamente ponderado, ya que, advierte el autor, existen, en primer lugar, decisiones internas que aunque tienen por objeto cuestiones relacionadas con el Derecho internacional, la aplicación del «enriquecimiento sin causa» no se hace en virtud de éste, sino del Derecho interno ${ }^{21}$; en segundo lugar, puede encontrarse jurisprudencia en la que la alusión al enriquecimiento sin causa no es más que una «apariencia terminología bajo la que se oculta el fundamento real de la decisión, que es otro distinto ${ }^{22}$; y, por último, destaca una serie de casos poco significativos en los que tan sólo hay una mención meramente incidental al «enriquecimiento sin causa $»^{23}$.

8. Es evidente que el eje de estudio por parte de la doctrina iusinternacional publicista gira en torno a la búsqueda de decisiones en las que se aplique la teoría del enriquecimiento sobre la base del Derecho internacional general y no de los distintos Derechos internos. En este sentido, el asunto de la Generale Finance Coorporation ${ }^{24}$ supone un hito debido a que en él se afirma que según el Derecho internacional se debe resarcir al actor en la medida en que se ha enriquecido injustamente.

9. Más interesantes desde una perspectiva internacional privatista son, sin embargo, las decisiones traídas de la práctica internacional de los tribunales arbitrales mixtos creados por los tratados de paz, al aplicar la doctrina del enriquecimiento sin causa como fundamento de la obligación de resarcimiento de prestaciones realizadas sobre la base de un contrato resuelto como consecuencia de la guerra y celebrado entre particulares nacionales de Estados pertenecientes a bandos distintos. En estos asuntos el problema de fondo era el del Derecho aplicable a una situación concreta en la que se había producido un enriquecimiento sin causa esto es, el Tratado de Versalles o los Derechos internos aplicables al litigio en cuestión. Así, en la decisión del Tribunal arbitral mixto angloalemán de 7 de mayo de 1929 en el asunto Iraq Petroleum company Ltd. v.

\footnotetext{
20 G. C. Rodríguez Iglesias, «EI enriquecimiento sin causa como fundamento...», cit., pp. 382
} y ss.

21 Sentencia del TS de Polonia de 14 diciembre 1928, asunto Zilberspic c. El Tesoro, Annual Digest of Public international Law Cases, 1927-28, p. 82; y la Sentencia del TS de Austria de 1948 en el asunto de los ferrocarriles alemanes en Austria, SZ 21/601948, cit. por G. C. Rodríguez Iglesias, cit., p. 382 nota 10.

22 G. C. Rodríguez Iglesias, cit., p. 383, esp. nota 11. En este grupo el autor cita las decisiones de la Comisión de reclamaciones entre Estados Unidos y Méjico de 3 de junio de 1927, Asunto George W. Cook c. United Mexican States, R. S. A., IV, pp. 223; y la de 18 de octubre de 1928, asunto United States of America on behalt of Francis J. Acosta v. United Mexican states.

23 V. gr. el Asunto de la Lybian American Oil Company (Liamco) v. The Goberment of the Lybian Arab Republic, LM, XX, 1981, p. 1 y ss. Un estudio detallado puede encontrarse en, C. Greenwood, «The state of contracts in international Law the Libian Oil arbitrations», The British Yearbook of international Law, vol, LIII, 1982, pp. 27 y ss.

24 Departament of State Publication 2859, Arbitration Series 9, p. 546. 
Deutsche Bank und Disconto Gesellschaft ${ }^{25}$ se aplica la doctrina del enriquecimiento sin causa como institución prevista en el Derecho alemán, ordenamiento jurídico designado como aplicable en virtud de la autonomía de la voluntad de las partes en litigio ${ }^{26}$.

Existen, no obstante, decisiones en las que se aplica el enriquecimiento sin causa como obligación derivada del propio tratado internacional. En el asunto Burroughs Wellcome and Co v. Chemische Fabrick auf Actien, el tribunal mantiene que «... whether a dissolved contract was subject to German or to English Law it is within the intentions of the Treaty that a party to the contract who has obtained a benefit at the expense of the other party since he was received on his part from further performance of the contract, may thereby be subject to a pecuniary obligation within the exception contained in Article $299 \gg^{27}$.

Al margen de estas decisiones el enriquecimiento sin causa no ha sido aplicado por los tribunales internacionales como institución de Derecho internacional; sí se ha aplicado, sin embargo, como principio general del Derecho reconocido tanto por los sistemas jurídicos estatales cuanto por el Derecho internacional, como se tendrá ocasión de comprobar a continuación.

\section{EL PRINCIPIO GENERAL DE ENRIQUECIMIENTO INJUSTO EN EL ORDEN INTERNACIONAL ${ }^{28}$}

\section{Planteamiento: principio interno versus principio internacional}

9. Del estudio de la doctrina y de la práctica del Derecho internacional puede observarse que la figura a la que se hace referencia habitualmente al hablar de

25 Rec. TAM, IX, p. 478 y ss.

26 EI Tribunal afirma que: «...are accordingly of opinion that the question whether the Claimants are entitled to claim a return of the value of the shares, is to be decided by reference to the municipal law applicable. It is, on this assumption, common ground between the parties that german Law is applicable. In accordance with the German Civil Code paragrafs 812 y 818 the Respondents are in the circonstances of the present claim, liable to refund to the Claimans what they have received in so far as they have been enriched thereby».

27 Vid. Rec. TAM, VI, pp. 13 y ss. Y en el mismo sentido se pronuncian los laudos arbitrales dictados con ocasión de los asuntos: Arnold and Foster Ltd. and J. W. Erkens (13 oct. 1926), (Rec. TAM, VI, pp. 606 y ss.); Leslie Caro V. Norddeutscher Lloyd, (17 junio 1927), (Rec TAM, VII, pp. 398 y ss.); la decisión del Tribunal Arbitral anglo-belga en el asunto Didier c. Cohn et Pink, (31 enero 1929), (Rec. $T A M$, VIII, pp. 800 y ss.); y, por último, la del Tribunal arbitral turco-inglés en el asunto Gouvernement turc c. Sir W. J. Amstrong Whitworth and $C^{\circ}$ Ltd. et Vickers Ltd, (Rec. TAM, VIII, pp. 996 y ss.).

28 Se excluye de este apartado el estudio del principio en el ámbito del Derecho comunitario, pero quizá convenga señalar que el estudio de la jurisprudencia del Tribunal de Justicia de la Unión Europea permite afirmar que existe una obligación de restituir los importes indebidos impuestos por el Derecho comunitario al margen de los sistemas estatales, como consecuencia del principio de Derecho comunitario que prohibe el enriquecimiento injusto; y que debido a la laguna legal existente en este Derecho respecto a las modalidades de la acción de restitución, procedimiento y condiciones para su ejercicio se produce un reenvío a los sistemas nacionales. Sobre esta cuestión vid., inter alia, L. Esteve González, «Fundamento...», cit., supra. 
«enriquecimiento sin causa» es, en realidad, la del principio general del Derecho que hemos venido denominando enriquecimiento injusto ${ }^{29}$ y que el problema planteado por la doctrina iusinternacionalista se centra, fundamentalmente, en dilucidar si existe un principio general de Derecho internacional que prohíba el enriquecimiento injusto - principio universal_ y que pueda ser el fundamento de la obligación de restituir en aquellos supuestos en los que dicha obligación no nace de un hecho ilícito o, por el contrario, es éste una mera trasposición del principio interno al orden internacional.

Para las tesis universalistas de los albores del siglo XX, que defienden la existencia de principios generales del Derecho comunes o de validez universal, no hay ninguna duda: el enriquecimiento injusto es un principio del Derecho internacional general. Desde esta perspectiva es interesante el planteamiento de J. Jitta respecto a la figura que nos ocupa. El autor, dentro de la concepción que rechaza la noción de cuasicontrato, distingue, sin embargo, dos figuras o principios generales del Derecho, el de «enriquecimiento sin causa» y el de la Condictio indebiti, para posteriormente afirmar que mientras la existencia del primero en Derecho internacional es dudosa, el principio de la condictio indebiti está reconocido por el Derecho común internacional ${ }^{30}$.

La doctrina iusinternacional publicista afirma mayoritariamente que el Derecho internacional público es susceptible de poseer sus propios principios generales del Derecho, pero también puede servirse de los ya conocidos y formulados desde antaño y procedentes del Derecho privado interno ${ }^{31}$, los denominados «prin-

29 Especial interés en la aplicación del enriquecimiento injusto a las relaciones internacionales tiene, entre otras, la Sentencia que originó el asunto Abatielos (Affaire Abatieros, Arrêt du mai 1953, en C.I.J. Rec., 1953, pp. 10 y ss.) entre Grecia y el Reino Unido, donde se negó la existencia del enriquecimiento injusto en el caso concreto, aunque no se discutió la aplicabilidad del principio en el orden internacional. Vid. también el asunto de la Lena Goldfields Corporation, Ltd. Arbitration and the soviet Govermment, 3 septiembre 1930 (Cornell Law Quarterly, XXXVI, 1950-51, pp. 42 y ss.) en el que el Tribunal arbitral afirmó que los principios generales reconocidos por las naciones civilizadas a los que se refiere el art. 38 del Estatuto del Tribunal Permanente de Justicia Internacional deben contemplarse como «the proper Law» de la concesión. La Decisión de 21 mayo 1921, adoptada en el asunto Landreau entre Perú y EEUU, en la que se estimó que el Gobierno de Perú debía pagar una compensación a los herederos de Landreau por los beneficios obtenidos por el descubrimiento de yacimientos de guano, sobre la base del Quantum meruit y, en fin, la Sentencia del Tribunal arbitral del Deragoa de 29 de marzo de 1900 (Martens, Nouveau Recueil, 2 ème serie, t. XXX, 1903, p. 329, esp. p. 401).

30 J. Jitta, La substance des obligations dans le droit international privé, t. II, La Haya, Belinfante, 1907, pp. 410 y ss. Esta afirmación formulada a principios de siglo podría ser matizada en el actualidad en dos sentidos: en primer término, es posible distinguir el principio general del Derecho de la fuente autónoma de las obligaciones y, en segundo lugar, existe doctrina y legislaciones -alemana, suiza, portuguesa, austríaca- que entienden que el cobro de lo indebido es un supuesto más de enriquecimiento sin causa.

31 Principio de Derecho interno que, según E. Jiménez de Aréchaga (Derecho internacional contemporáneo, Madrid, Tecnos, 1980, p. 357) «...no se puede trasladar mecánicamente, en todos sus aspectos a la órbita del Derecho internacional. Estos principios de derecho interno deben considerarse más bien como (cita el autor una frase textual de MacNair) 'una indicación de política y principios'». 
cipios generales reconocidos por las naciones civilizadas» ${ }^{32}$, que serán, en cualquier caso, fuente jurídica según el art. 38 del Estatuto del Tribunal internacional de Justicia ${ }^{33}$, como es el caso del viejo principio de enriquecimiento injusto ${ }^{34}$. Y es que, en realidad, la mayoría de los principios generales del Derecho han sido desarrollados en la doctrina de Derecho civil y su explicación es muy simple: el Derecho civil es prioritario en el tiempo al Derecho internacional $-\mathrm{y}$ al Derecho público en general- Según K. Wolff, un principio de Derecho civil puede o no ser aplicado a las relaciones internacionales; si lo es, es porque se trata de un «principle généraux de droit entier», es decir, un «principle générale de droit pris dans son ensamble» ${ }^{35}$.

\section{Valor normativo del principio}

10. Que el enriquecimiento injusto es un principio general del Derecho aplicable a las relaciones internacionales es un hecho mayoritariamente aceptado por la doctrina y jurisprudencia internacional y debería desplazar la cuestión de si es un principio interno o un principio universal aplicable también a las relaciones internas. Tras esta premisa, el interés se orienta hacia la determinación del valor normativo y teórico de dicho principio en el ámbito internacional.

Los trabajos de la Comisión de Derecho Internacional (CDI) sobre la codificación de las normas relativas a la responsabilidad de los Estados y, en especial, en lo referente a la sucesión de Estados nos ayudan a despejar algunas dudas. En el primer supuesto, el informe de la subcomisión para la responsabilidad internacio$\mathrm{nal}^{36}$, supuso una nueva orientación al no restringir el estudio de la responsabilidad de los Estados a la responsabilidad por daños ${ }^{37}$. En efecto, la Comisión ha destacado el diferente fundamento que tienen la responsabilidad derivada del hecho ilícito y la responsabilidad por actos no prohibidos por el Derecho interna-

32 Vid., per omnia, Lord MacNair, «The general principles of law recognized by Civilized Nations», The British Yearbook of International Law, XXXIII, 1957, pp. 1-19.

33 En este sentido, vid. W. Friedmann, «The principle of Unjust Enrichment in English Law», The Canadian Bar Rev., cit., p. 244. Hay que subrayar que la fórmula del art. 38 en su referencia a los principios generales del Derecho como fuente autónoma del Derecho internacional ha suscitado una amplia controversia doctrinal sobre la naturaleza de estos principios, controversia que recoge B. Vitany en su trabajo: «Les positions doctrinales concernant le sens de la notion de 'principles generaux de droit reconnus par les nations civilisées», Rev. Int. Dr. Int. Public, t. 86, 1982, pp. 48-116.

34 Cfr. A. Miaja de la Muela, «El principio de enriquecimiento...», cit. p. 350.

35 Vid. K. Wolff, «Les principles généraux de Droit applicables dans les rapports internationaux», Rec. des Cours, XXXVI, 1931, pp. 483 y ss.

36 Vid. informe redactado por R. Ago en Anuario CDI, 1969, vol. III, y 1973, vol. II.

37 El alcance del proyecto se limita a la codificación de las normas llamadas «secundarias», con exclusión de las normas primarias de donde derivan esas obligaciones (vid. Anuario CDI, 1976, vol. II, $2^{\mathrm{a}}$ parte, p. 68 ). Sobre las circunstancias que impulsaron a la CDI a reanudar desde este nuevo planteamiento el estudio de la cuestión de la responsabilidad de los Estados, vid. Anuario CDI, 1969, vol. II, pp. 240 y ss. 
cional —es decir, actos que, no siendo ilícitos, generan responsabilidad internacional- donde podría incluirse la figura del enriquecimiento $\sin$ causa $^{38}$, si bien ésta no se prevé de forma específica en los trabajos de la Comisión. En el segundo aspecto, el de la sucesión de Estados ${ }^{39}$, atribuye relevancia decisiva a la noción de equidad como criterio para la solución de la cuestión de la trasmisión de deudas de Estado, lo que podría interpretarse sobre la base del enriquecimiento injusto ya que el carácter de éste como principio equitativo es generalmente destacado ${ }^{40}$. Por otra parte, del texto del art. 36 del Proyecto de artículos sobre sucesión de Estados $^{41}$ puede desprenderse su inspiración en el principio de enriquecimiento injusto aunque éste no se mencione expresamente ${ }^{42}$.

11. Dejando a un lado los intentos de codificación y volviendo a la labor de la jurisprudencia, puede afirmarse que no existe una norma consuetudinaria que prohíba el enriquecimiento injusto, pero sí hay indicios suficientes que permiten corroborar la existencia de un 'principio general reconocido por las naciones civilizadas' y aplicable a las relaciones internacionales, opinión que es, por otra

38 Vid. Anuario CDI, 1973, vol. II, p. 172, párrafo 38. Véanse, además, el «Informe Preliminar sobre la responsabilidad internacional por las consecuencias perjudiciales de actos no prohibidos por el Derecho internacional», redactado por R. Q. Quentín-Baxter, en Anuario CDI, 1980, vol. II, (1 ${ }^{\text {a }}$ parte), pp. 259 y ss.

39 Vid. Proyecto de artículos sobre la sucesión de Estados en materia de bienes, archivos y deudas de Estado, en Anuario CDI, 1981, vol. II, $2^{\mathrm{a}}$ parte, pp. 21 y ss.

40 Cfr. informe de la CDI (A/36/10) y en particular los comentarios al art. 35 del Proyecto de artículos sobre sucesión de Estados (Anuario CDI, 1981, vol. II, segunda parte, pp. 34 y ss. y, especialmente, 211 y 247-249). El art. 35 dispone que «1. Cuando una parte del territorio de un Estado sea traspasada por éste a otro Estado, el paso de la deuda de Estado del Estado predecesor al Estado sucesor se determinará por acuerdo entre ellos. 2. A falta de un acuerdo, la deuda de Estado del Estado predecesor pasará al Estado sucesor en una proporción equitativa, habida cuenta en particular de los bienes, derechos e intereses que pasen al Estado sucesor en relación con esta deuda de Estado», (vid. Anuario CDI, 1981, vol. II, $2^{\mathrm{a}}$ parte, p. 87).

41 El texto de1 art. 36 es el siguiente: «1. Cuando el Estado sucesor sea un Estado de reciente independencia, ninguna deuda de Estado del Estado predecesor pasará al Estado de reciente independencia, a menos que un acuerdo entre el Estado de reciente independencia y el Estado pedecesor disponga otra cosa por razón del nexo entre la deuda de Estado del Estado predecesor vinculada a la actividad en el territorio al que se refiere la sucesión de Estados y los bienes, derechos e intereses que pasen al Estado de reciente independencia. 2. El acuerdo a que se refiere el párrafo I no podrá menoscabar el principio de soberanía permanente de cada pueblo sobre sus riquezas y sus recursos naturales, ni su cumplimiento podrá poner en peligro los equilibrios económicos fundamentales del Estado de reciente independencia», (vid. Anuario CDI, 1981, vol. II, $2^{\mathrm{a}}$ parte, pp. 94 y 95).

42 Cfr. G.C. Rodríguez Iglesias, loc. cit. p. 380. Existe otro enfoque en virtud del cual las actividades no prohibidas derivan tan sólo del Derecho convencional y no tienen una base clara en el Derecho consuetudinario por lo que no pueden extenderse a materias no reguladas por instrumentos convencionales específicos (vid. comentarios en el seno de la CDI de J. Barboza en Anuario CDI, 1980 , vol. II, $2^{\mathrm{a}}$ parte, pp. 93 y ss.). 
parte, comúnmente aceptada por la doctrina internacionalista ${ }^{43}$. El principio general del Derecho que prohíbe el enriquecimiento injusto participa, por tanto, de la doble condición de ser común a los distintos sistemas y de ser aplicable a las relaciones internacionales ${ }^{44}$.

El problema versa en cómo aplicarlo, lo que centra la polémica en la cuestión ya abierta relativa a la consideración de estos «principios generales del Derecho reconocidos por las naciones civilizadas ${ }^{45}$ como fuente autónoma del Dip. distinta de la costumbre y los tratados o, por el contrario, su consideración como normas de Dip. en la medida en que son recogidos en tratado o costumbre ${ }^{46}$. La forma de aplicación de los principios generales para esta última doctrina parece evidente: se hará siempre por vía de tratado o costumbre; respecto a la primera postura, la doctrina considera que el Tribunal internacional no transvasará de manera automática al problema de Derecho internacional el principio de Derecho interno, en palabras de C. Gutiérrez Espada «el juez debe inducir; y por otra parte, el principio inducido debe ser aplicable a la situación o problema internacional dado» ${ }^{47}$.

\section{Función del principio en las relaciones internacionales. Especial referen- cia a su función informativa del orden público internacional}

12. Si es innegable la existencia del principio general del Derecho como principio común a todos los sistemas jurídicos - lo que, en palabras de L.J. Constantinesco, se denomina «constantes generales» ${ }^{48}$ - lo importante es determinar cuál es el valor práctico de dicho principio en las relaciones internacionales $\mathrm{y}$ tener presente que «en droit international, en droit international privé et dans l'arbitrage international, leur application dépend des dispositions indiquant les sources juridiques applicables dans le cas concret. Les principes généraux peuvent devenir du droit positif si les parties contratans, le législateur ou la jurisprudence les reconaissent en tant que tel ${ }^{49}$. El enriquecimiento injusto ha sido —como ya

43 Vid. G. C. Rodríguez Iglesias, «El enriquecimiento sin causa...», cit., pp. 387 y ss. Entre la doctrina favorable a la admisión del principio en Derecho internacional, vid. G. Rippert, «Les règles de droit civil applicables...», loc. cit., pp. 569 y ss.; E. Fanara, op. cit. supra; E. Jiménez de Aréchaga, op. cit. supra; Miaja de la Muela, cit. supra; C.H. Schreuer, cit. supra. En contra, sin embargo, vid., per omnia, G. Balladore-Pallieri, Diritto internazionale pubblico, $7^{\mathrm{a}}$ ed., Milán, 1956, pp. 339 y ss.

44 G. C. Rodríguez Iglesias, cit., pp. 387 y 388.

45 Ya ha habido ocasión de destacar la controversia doctrinal existente en torno a estos principios en la nota 33 del presente trabajo.

46 Se trata de un amplio debate que escapa del objeto del presente trabajo pero que parecía necesario apuntar; vid., al respecto, C. Gutiérrez Espada, Hacia un compendio de Derecho internacional público, Barcelona, PPU, 1991, pp. 107 y ss.

47 C. Gutiérrez Espada, Hacia un compendio de Derecho internacional ..., op. cit., p. 114.

48 J. L. Constantinesco, Traité de droit comparé, t. II, París, LGDJ, 1974, pp. 287 y ss.

49 Ibidem., p. 298, nota 53. 
se ha indicado- aplicado en numerosas ocasiones por la jurisprudencia arbitral y en muy raras ocasiones por el Tribunal de Justicia de la Haya ${ }^{50}$. En efecto, la limitada aplicación de estos principios por los tribunales internacionales no se plantea en sectores jurídicos que se desarrollan al margen del Tribunal Internacional de Justicia e inciden en la contratación internacional y en su aplicación e interpretación por los tribunales arbitrales internacionales. Es aquí, en la jurisdicción arbitral en la que es de gran importancia —habrá ocasión de volver sobre ello- el recurso a los principios generales del Derecho ${ }^{51}$.

La función principal del enriquecimiento injusto en Dip. ha sido, según A. Miaja de la Muela, la de actuar como límite a las pretensiones de reparación del Estado demandante para que, en caso de que sea excesiva en relación al empobrecimiento sufrido, no diese lugar a un enriquecimiento «sin causa» - función moderadora - y como fundamento de la responsabilidad internacional del Estado indebidamente enriquecido a expensas de un particular extranjero, el que se convierte en acreedor de una justa compensación por el empobrecimiento correlativo - función reparadora ${ }^{52}$ - y, muy especialmente, subraya su utilización como fundamento de la indemnización al perjudicado por las expropiaciones y nacionalizaciones de bienes extranjeros ${ }^{53}$-, lo que se podría denominar función compensadora.

El valor teórico del enriquecimiento injusto en la práctica internacional es evidente: la recepción en el orden internacional del principio que nos ocupa responde a unas premisas indiscutibles que se adscriben a los principios capitalistas y desbordan el ámbito estatal desarrollándose en las relaciones internacionales. Principios de Derecho patrimonial - entre otros el de propiedad privada, autonomía de la voluntad, conmutabilidad de las prestaciones en el comercio jurídico, buena fe, moralización del tráfico económico- que, en la actualidad, tras los profundos cambios que ha sufrido la Comunidad Internacional -especialmente en los países del Este- son comunes en la mayoría de las naciones y

50 Vid., v. gr. el asunto Abamtielos (cit. supra), en el que en realidad el Tribunal no se pronunció sobre el problema del enriquecimiento.

51 W. Friedman, La nueva estructura del Derecho internacional, México, Ed. Trillas, 1967, p. 232.

52 A. Miaja de la Muela (cit. pp. 352 y ss.) habla de las reivindicaciones basadas en el enriquecimiento sin causa y nacidas del Nuevo Orden Económico Internacional por las cuales los Estados del Tercer Mundo piden lo suyo o un equivalente pecuniario y alegan las expoliaciones que sus riquezas naturales han sufrido durante el periodo en que estuvieron sometidas al colonialismo de las grandes potencias.

53 Vid. A. Miaja de la Muela, cit., pp. 360 y ss. En efecto, «el campo privilegiado de aplicación» del enriquecimiento sin causa en Derecho internacional general es el de la responsabilidad del Estado por dahos causados a intereses económicos de particulares extranjeros y el de la compensación por nacionalizaciones (vid. G. C. Rodríguez Iglesias, cit. pp. 390 y ss.). Sobre este último supuesto, vid. también E. Jiménez de Aréchaga, op. cit. pp. 355 y ss. El enriquecimiento injusto ha sido aplicado, además, para explicar, en el ámbito de la sucesión de Estados, los problemas relativos a la trasmisión de deuda pública del Estado predecesor al Estado sucesor. 
en los llamados regímenes socialistas ${ }^{54}$ y sin duda en los países de mayor poder económico ${ }^{55}$. Son principios, en definitiva, dirigidos por el que prohibe el enriquecimiento injusto.

De ello puede desprenderse que el principio general del Derecho enriquecimiento injusto «reconocido por todas las naciones civilizadas» y aplicable a las relaciones internas e internacionales tendrá como última función -la más relevante a efectos del estudio iusinternacionalprivatista - la de ilustrar, a través de los valores jurídicos que de él se predican, el orden público internacional. Esta afirmación no debe interpretarse en el sentido de que estemos ante una institución de orden público ${ }^{56}$. Y es precisamente la distinción entre enriquecimiento injusto y enriquecimiento sin causa la que permite argumentar en contra de su carácter de orden público. Respecto a la fuente autónoma de las obligaciones, las limitaciones de que es objeto por parte de los distintos ordenamientos jurídicos estatales en pro de la seguridad jurídica y las condiciones que pretenden evitar un desbordamiento excesivo de la acción son condiciones desfavorables para el análisis del enriquecimiento sin causa como institución de orden público internacional. El principio general del Derecho «enriquecimiento injusto» es capaz de ilustrar el orden público internacional pero ello no significa que deba rechazarse por principio el Derecho extranjero designado por una norma de conflicto, sino que este principio debe actuar en su labor informativa, justificativa y, en su caso, correctiva de las consecuencias injustas que la aplicación rigurosa del Derecho pudiera ocasionar: el problema debe plantearse en relación a supuestos concretos y no a cláusulas generales ${ }^{57}$.

\section{INCIDENCIA DEL DERECHO INTERNACIONAL GENERAL EN EL SECTOR DEL DERECHO APLICABLE EN MATERIA DE ENRIQUE- CIMIENTO INJUSTO}

13. El principio general del Derecho que prohíbe el enriquecimiento injusto está reconocido, como ya se ha indicado, en todos los Derechos internos e incluso es aplicable en las relaciones internacionales integrándose en aquellos principios a los que hace referencia el art. 38 del Estatuto del Tribunal Internacional de

54 Vid. V. Knapp, «Die Ungerechtfertigte Bereicherung in der Rechten der europäischen sozialischen Länder», Zweigert-Fschr, 1981, pp. 465-480.

55 Vid. L. Díez-Picazo, Fundamentos del Derecho civil patrimonial, Madrid, Tecnos, 1970, pp. 42 y ss. ( $4^{\text {a }}$ ed. Madrid, Civitas, 1993).

56 En este sentido G. Légier, «Les conflits de lois relatifs a l'enrichissement sans cause», Mélanges en l'honeur du professeur J.P. Béquet, Faculté du Droit Université de Toulon et du Var, 1985, pp. 167-197. La jurisprudencia francesa decimonónica fue la que más insistió en su carácter de orden público (vid. por todas, la Sentencia del Tribunal civil del Sena, de 4 de junio de 1886, Journ., dr. int., t. XIV, 1887, pp. 178 y ss.).

57 Vid., per omnia, H. Batiffol, «Quelques précisions sur le domaine de l'excepción d'ordre public», Studi onore di Giorgio Balladore Pallieri, vol. II, Milán, Vita, 1978, pp. 35 y ss., esp. p.41, al tratar el problema de las nacionalizaciones sin una justa indemnización. 
Justicia, llegando también a formar parte de los principios generales del Derecho comunitario $^{58}$. Y puede afectar a la regulación de los supuestos de tráfico jurídico internacional objeto del Dipr., más concretamente, al problema de la determinación de la ley aplicable. La aplicación de los «principios generales del Derecho reconocidos por las naciones civilizadas» es una clara muestra, además, de la materialización de la incidencia del Derecho internacional general en Dipr., concretamente en el sector de la ley aplicable ${ }^{59}$.

En efecto, este principio general ha sido invocado en diferentes ocasiones no sólo como parte integrante del Derecho interno que resultaría aplicable sino también como parte de «los principios generales del Derecho reconocidos por las naciones civilizadas» y contemplados como lex contractus. El asunto Lena Goldfields Ltd. and the soviet Government, decidido en Sentencia de 3 de septiembre de 1930, es un claro ejemplo de esta última afirmación ${ }^{60}$. El objeto del litigio versaba sobre una concesión otorgada por las autoridades - por aquel entonces- soviéticas a una compañía británica, Lena Goldfields, la cual se sintió perjudicada debido a una serie de actos legislativos y administrativos del gobierno soviético que infringían claramente las obligaciones derivadas del contrato, por lo que la compañía decidió poner en marcha el procedimiento arbitral previsto en el acuerdo de concesión, basándose en las acciones de breach of contract y de unjust enrichment. El Tribunal arbitral aceptó los argumentos alegados por la compañía en virtud de los que, por un lado, en «todas las materias domésticas» (domestic matters) era aplicable el Derecho soviético, excepto en la medida en que fuese excluido por el contrato y, por otro, en las demás materias eran aplicables «los principios generales reconocidos por las naciones civilizadas», que deben contemplarse como «the proper Law of the contract», y al encontrarse el principio de enriquecimiento injusto entre ellos - por estar reconocido en el Derecho contractual soviético y británico- se debía compensar a la Compañía Lena ${ }^{61}$. Conviene

58 Vid., inter alia, L. Esteve González, «Fundamento...», cit. supra.

59 Cfr., J.C. Fernández Rozas y S. Sánchez Lorenzo, Curso de Derecho internacional privado, cit., pp. 424 y ss.

60 Cit. supra, Cornell Law Quarterly, XXXVI, 1950-51, pp. 42 y ss. Vid. además, sobre la misma, A. Nussbaum, «The Arbitration between the Lena Goldfields, Ltd. and the Soviet Goverment» Cornell law Quartely, cit., pp. 31 y ss.; Lord MacNair «The General Principles of Law recogniced by Civilized Nations», loc. cit., 1957, pp. 10 y 11; y J.C. Fernández Rozas y S. Sánchez Lorenzo, Curso de Derecho internacional..., cit., pp. 424 y 425.

61 En el mismo orden de ideas se sitúa la Sentencia del Tribunal arbitral del Deragoa de 29 de marzo de 1900 (cit., p. 329), donde se plantea el fundamento de la obligación de compensación de Portugal debido a la inejecución de un compromiso contractual. El Tribunal llega a la conclusión de que ha habido un comportamiento ilícito por parte de Portugal lo que determina que el principio aplicable a la restitución sea el de daños y perjuicios y no el de enriquecimiento injusto. Pero el valor de esta decisión - a los efectos de la cuestión que nos ocupa - radica en que el Derecho aplicable era, según el tribunal, el portugués, pero en la Sentencia se pone de manifiesto que la cuestión es de alcance meramente teórico, ya que la ley portuguesa no contiene ninguna disposición particular que se aparte de los «principios generales del Derecho común de las naciones modernas». 
recordar, por otra parte, que la aplicación de estos principios a elección de las partes junto con la aplicación de dos o más leyes (dépeçage) en contratos celebrados entre sujetos en los que uno tiene personalidad jurídica internacional no es una práctica extraña y ello se justifica por el carácter especial de estos contratos, la tensión de intereses subyacentes y sobre todo, el alto riesgo contractual que ambas partes asumen al contratar ${ }^{62}$. La puesta en escena del principio de enriquecimiento injusto puede ser muy eficaz en el arbitraje comercial internacional.

\section{CONCLUSIONES}

14. Del estudio del enriquecimiento injusto y sin causa en Derecho internacional general pueden deducirse las siguientes conclusiones con repercusiones en Derecho internacional privado:

1. La «dogmática del enriquecimiento sin causa» se ha proyectado en las relaciones internacionales de Derecho público. Respecto a la fuente autónoma de las obligaciones, tan sólo se ha aplicado en el Dip. como institución reconocida por los sistemas estatales y no como fuente autónoma de las obligaciones de carácter internacional. El principio general del Derecho enriquecimiento injusto ha sido reconocido por cierto sector doctrinal como principio de Derecho internacional y tiene una doble condición: la de ser común a todos los Derechos y aplicable a las relaciones internacionales. En cualquier caso se trata de uno de los «principios generales del Derecho reconocidos por las naciones civilizadas» que expresa los valores superiores que deseablemente debería tener todo ordenamiento jurídico: justicia, libertad e igualdad; y es, por ello, susceptible de ilustrar el orden público internacional.

2. La distinción entre enriquecimiento injusto y enriquecimiento sin causa permite concluir que la fuente autónoma de las obligaciones no tiene carácter de orden público internacional y que el principio general del Derecho «enriquecimiento injusto», informador de la excepción de orden público internacional, debe aplicarse en las relaciones internacionales tanto públicas cuanto privadas de for-

62 Vid., verbi gratia, Petroleum Concession Agreement of October 23, 1963, between the Goverment of the United Arab Republic, Egyptian Petroleum Corporation and Pan American UAR Oil Company, (art. 42), cit. J. Carrascosa González, El contrato internacional (fraccionamiento versus unidad), Madrid, Civitas, 1992, pp. 203 y ss. La cuestión está vinculada, de nuevo, a la discusión teórica sobre si estos principios pueden aplicarse como principios autónomos, o tienen que ser partes del Derecho estatal designado aplicable. Vid. respecto de la aplicación de los principios de UNIDROIT relativos a los contratos comerciales internacionales $H$. van Houtte, «The UNIDROIT Principles of International Commercial Contracts», Arbitration International, vol. 11, 1995, pp. 373 y ss., esp. p. 381 y ss. 
ma coherente con sus funciones integradora, informadora, explicativa y justificativa del Derecho.

3. En particular, el enriquecimiento injusto puede ser aplicado en las situaciones privadas internacionales como «principio general del Derecho reconocido por las naciones civilizadas», bien directamente activando una norma imperativa reflejo de los valores anteriormente citados, o bien como the proper law. Y puede ser también aplicado como principio de Derecho interno si éste está previsto por la lex causae, la lex loci o la lex fori, en el supuesto de que el Derecho designado por la norma de conflicto no ofrezca una respuesta satisfactoria al concreto problema planteado. 